\title{
Use of population fitness to evaluate the nursery function of juvenile habitats
}

\author{
F. Joel Fodrie ${ }^{1,2, *}$, Lisa A. Levin ${ }^{1}$, Andrew J. Lucas ${ }^{1}$ \\ ${ }^{1}$ Integrative Oceanography Division, Scripps Institution of Oceanography, La Jolla, California 92093-0218, USA \\ ${ }^{2}$ Present address: University of South Alabama \& Dauphin Island Sea Lab, 101 Bienville Boulevard, Dauphin Island,
} Alabama 36528, USA

\begin{abstract}
Juveniles of many fish and invertebrate species are able to select among a diverse portfolio of nursery habitat alternatives. Environmental heterogeneity among these habitats generates variation in the vital rates of young individuals that may influence overall population dynamics. Therefore, understanding how these habitat options affect population fitness is crucial for identifying habitats that widen bottlenecks in early life histories and promote population persistence. We used cohort analyses and demographic models to explore the population-level consequences of habitat selection by juvenile California halibut Paralichthys californicus in southern California, focusing on population growth rate $(\lambda)$ as a measure of fitness. Although alternative juvenile habitats (exposed coast and coastal embayments) could contribute an approximately equal number of recruits to the adult stock, positive overall population growth $(\lambda>1)$ depended critically on the subpopulations of juveniles that utilized coastal embayments (bays, lagoons, and estuaries). Conversely, the juvenile subpopulation along the exposed coast contributed negatively to overall population growth $(\lambda<1)$ in 3 of the 4 years we conducted this study, due to elevated local mortality in that habitat. Life table response experiments confirmed that juvenile growth and survivorship were responsible for differences in $\lambda$, and that nursery habitat choice could be a key contributor toward overall population fitness. Considering nurseries in a demographic source-sink context could aid conservation efforts by allowing identification or prioritization of the juvenile habitats most critical for population persistence.
\end{abstract}

KEY WORDS: Nursery · Fitness · Demography · Life table response experiments · Source-sink · Matrix models $\cdot$ Paralichthys californicus $\cdot$ California halibut

\section{INTRODUCTION}

Marine environments are spatially heterogeneous, with consequences for many of the processes that affect population dynamics such as foraging, reproduction, and recruitment (Levin \& Stunz 2005). Because early life-history stages are thought to contain many of the bottlenecks that regulate population size (Limburg 2001), understanding how species cope with habitat patchiness early in life is particularly important. Examples in which heterogeneity may have subsequent demographic effects include nesting choices by birds (Kauffman et al. 2003), oviposition site selection by insects (Doak et al. 2006), or the siting of reserves in the ocean (Gerber et al. 2005). In marine ecosystems, one of the most prominent forms of intraspecific habitat partitioning involves the use of inshore habitats as nurseries by juvenile fishes and crustaceans (Gillanders et al. 2003). Generally, this segregates life-history stages between nearshore and offshore environments, and members of the juvenile class among several inshore habitat alternatives. Despite efforts that predate description of the 'niche' (Petersen 1896, Grinnell 1917), ecologists have had difficulty in producing quantitative measures of habitat value in promoting population persistence for almost all species that utilize 'specialized' habitats during early life stages.

Recently, there has been renewed attention toward explicitly defining the functional role of putative nurseries in supporting fish and invertebrate stocks in an 
effort to optimize species conservation by prioritizing use of limited management resources. The most influential frameworks for evaluating nursery value have focused on the contribution of juvenile habitats towards production of adult biomass, either on a unit-area (Beck et al. 2001) or absolute scale (Gibson 1994, Dahlgren et al. 2006). A practical limitation of both approaches is that they assess habitats based only on the fate of successful recruits, and neither was designed to consider how integrated measures of juvenile growth and mortality affect overall population demography and growth rate $(\lambda$, also referred to as fitness). Given the substantial effort committed to document the differences in instantaneous growth and survivorship experienced by juveniles among habitats (see Heck et al. 2003 and references therein), and the obvious utility of population fitness as an integrated metric that could be applied in resource management (Mangel et al. 2006), it is surprising that the quantitative effects of juvenile habitat utilization on population growth have been largely neglected in the debate over nursery value.

The California halibut Paralichthys californicus exemplifies the life history of many nearshore demersal finfish. Broadcast spawning by adult halibut occurs in nearshore waters (Allen \& Herbinson 1990), and halibut larvae remain in surface waters over the continental shelf for $\sim 1$ mo (Moser \& Pommeranz 1999) before settling in shallow-water, exposed, coastal habitat (Allen \& Herbinson 1990). Before reaching $30 \mathrm{~mm}$ standard length (SL), some halibut immigrate to coastal embayments (Kramer 1990, Fodrie unpubl. data). Thus, subpopulations of juveniles are segregated among alternative 'nursery' habitats that differ greatly in abiotic (e.g. temperature, water clarity) and biotic (prey and predator fields) characteristics (Kramer 1991, Fodrie \& Mendoza 2006). At $\geq 1$ yr of age, all halibut egress from juvenile habitats and recruit to the nearshore subadult population located in waters $>10$ m deep (Kramer 1991) (Fig. 1). During the period between entry into a juvenile habitat at $30 \mathrm{~mm}$ SL and egression 12 mo later, juveniles make smallscale movements within a habitat, but do not typically migrate between alterative nursery types (Kramer 1991, Fodrie unpubl. data). Despite the portfolio of habitats that contribute toward juvenile recruitment to adult stocks, including both exposed coastal and protected embayment habitats (Fodrie \& Levin 2008), this species has been identified as the major estuarinedependent fishery species in southern California based largely on elevated abundances of juveniles in estuary habitats (e.g. Allen \& Herbinson 1990, Kramer 1991).

We used stage-structured matrix models (Lefkovitch 1965) combined with habitat-specific cohort analyses to generate estimates of population growth for south-

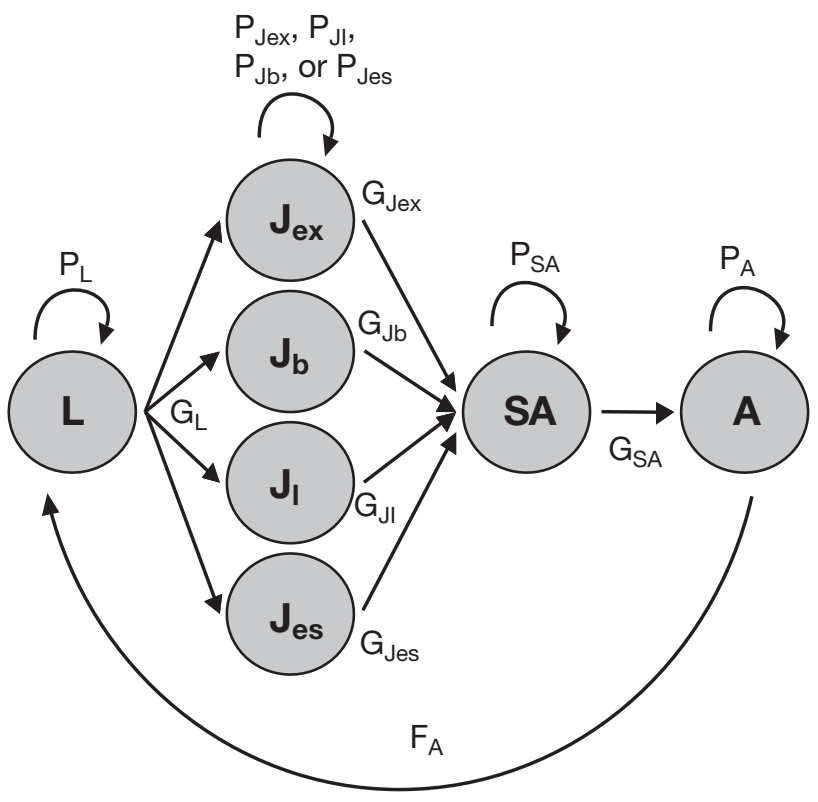

Fig. 1. Paralichthys californicus. Life-cycle diagram used to construct stage-based population projection matrix models for 4 California halibut subpopulations among juvenile habitat alternatives: exposed coast (ex), bay (b), lagoon (l), and estuary (es). L: larvae; J: juvenile; SA: subadult; A: adult. $P_{i}$ is the probability of surviving to remain in the same stage during 1 time step. $G_{i}$ is the probability of surviving and advancing to the next life-history stage during 1 time step. $P_{\mathrm{J}}$ and $G_{\mathrm{J}}$ are divided among subpopulations during the juvenile phase as a function of habitat utilization. $F_{\mathrm{A}}$ is the contribution of offspring by individual adults to the L stage during 1 time step

ern California halibut subpopulations that used each of 4 different juvenile habitats: exposed coasts, bays, lagoons, and estuaries. Specifically, we asked: (1) to which vital rates (growth, survivorship, or fertility) is $\lambda$ most sensitive, and how sensitive is $\lambda$ to these rates during the juvenile phase? (2) Are juvenile vital rates modified by habitat heterogeneity, and, if so, how does this variability contribute to observed differences in $\lambda$ among subpopulations that utilize different habitats, as well as fitness of the overall halibut population?

\section{MATERIALS AND METHODS}

Juvenile habitats, life-history information, and data gathering. Demography of the California halibut Paralichthys californicus was examined within 4 unique juvenile habitats along the coastline of San Diego County, California, USA. Juvenile halibut can occupy environments characterized as exposed coast or embayment, with the latter defined further as bays, lagoons, or estuaries (Fodrie \& Mendoza 2006). Our demographic expectations were based on previous results showing that mortality and, to a lesser extent, 
growth differed among juvenile habitat alternatives. Kramer $(1990,1991)$ extensively surveyed halibut populations within our study region in every month during 1987 and 1988 inside exposed coast (La Jolla, CA), bay (Mission Bay, CA) and lagoon (Agua Hedionda, CA) habitats to determine the size-frequencies of juvenile fish. Those data indicated significant survival advantages for newly settled fish in bays and lagoons, and slight growth advantages for larger juveniles in these 2 embayment types. We extracted the monthly sizefrequency data from Kramer (1990), which was generated from $>3300$ individual 5 min beam trawls that resulted in the collection of 6486 juvenile halibut, to explore the population-level consequences of habitatspecific differences in growth and survivorship.

We also duplicated Kramer's survey methods on a much smaller scale (we made 108 individual collections, resulting in 973 juvenile halibut captured), with new field sampling in 2002 and 2003, to generate additional estimates of mortality and growth within exposed coast (La Jolla) and bay (Mission Bay) habitats, as well as 1 estuary habitat (Tijuana River, CA).

Although habitats were non-replicated in our surveys, classification schemes to describe coastal embayments along the arid coastline of southern California support these sites as yielding representative habitatspecific vital rates and juvenile productivity within this region. Bays, lagoons and estuaries differ in total size, average depth, wetland cover, hydrologic modification, and ichthyofaunal community composition, and potentially function very differently as juvenile habitat (Ferren et al. 1996, Fodrie \& Mendoza 2006). For instance, all bays $(\mathrm{n}=3)$ in our study region are characterized by low-tide surface areas $>84$ ha, average depths $>4 \mathrm{~m}$, and area-to-perimeter ratios $>10$ ha $\mathrm{km}^{-1}$. Bays are kept open and relatively deep, to serve as harbors for shipping and recreational boating. Lagoons $(\mathrm{n}=3)$ are characterized by low-tide surface areas of 35 to $84 \mathrm{ha} \mathrm{km}^{-1}$, average depths of $\sim 3 \mathrm{~m}$, and area-to-perimeter ratios between 2.4 and $8.4 \mathrm{ha} \mathrm{km}^{-1}$. Estuaries $(\mathrm{n}=4)$ are described by low-tide surface areas $<25$ ha and average depths $<2.5 \mathrm{~m}$. Estuaries are also characterized by high wetland (salt marsh) cover, resulting in low area-to-perimeter ratios $\left(<2 \mathrm{ha} \mathrm{km}^{-1}\right)$. Furthermore, each of these embayment types supports different average juvenile halibut densities, while local densities are similar among embayments of the same basic type (Fodrie \& Mendoza 2006).

Our monthly censuses for juvenile halibut were completed in each habitat during 2002 and 2003, using trawls (Scripps, Mission Bay, and previously in Agua Hedionda) or block-net seining (Tijuana River). Trawling consisted of 3 tows, each lasting $10 \mathrm{~min}$, pulled behind a small research vessel $(<7 \mathrm{~m})$ at $2.5 \mathrm{~km} \mathrm{~h}^{-1}$. Trawl dimensions were as follows: $45 \times 90 \mathrm{~cm}$ doors,
$9.5 \mathrm{~m}$ headrope, $2.0 \mathrm{~cm}$ mesh in the main trawl body, and a $0.5 \mathrm{~cm}$ bag mesh. Similarly, 3 sets of block-nets and seine-pulls were used to quantify the sizefrequency of juvenile halibut within Tijuana River. Block-net seining involved passing 2 nets $(1.0 \mathrm{~cm}$ mesh) across marsh channels within the estuary to trap fish, and then dragging a beach seine $(1.0 \mathrm{~cm}$ mesh in the main body and $0.5 \mathrm{~cm}$ bag mesh) between the blocking nets until no halibut were collected on 2 consecutive drags of the seine. Halibut tended to be spatially restricted to a small section of the Tijuana River near the inlet mouth, aiding in our collection of individuals at this site. Fish were collected to define the relative abundance and size-frequency distribution of the local population from month to month, divided into $20 \mathrm{~mm}$ bins (selected to match the data available from Kramer [1990]), ranging from 40 to $220 \mathrm{~mm}$ SL (see Fig. 2).

We divided the halibut life cycle into 4 stages: (1) based on fish length and life-history transitions (Fig. 1): larvae (L: egg to $10 \mathrm{~mm} \mathrm{SL}$ ), juvenile (J: 10 to $220 \mathrm{~mm}$ SL), subadult (SA: 220 to $475 \mathrm{~mm} \mathrm{SL}$ ), and adult (A: $>475 \mathrm{~mm}$ SL). The division between $\mathrm{L}$ and $\mathrm{J}$ stages was based on settlement from the water column by larvae ready to begin life in the demersal stage. $\mathrm{J}$ and SA stages were distinguished based on the timing of juvenile egression from primary juvenile habitats (Kramer 1991) and $50 \%$ male maturity, while SA and A stages were separated by the timing of $50 \%$ female maturity (Love \& Brooks 1990).

Subsequently, habitat- and year-specific data on the number of juvenile halibut collected each month from each of the 4 juvenile habitat alternatives were imported into cohort life tables (e.g. Table 1), and from these tables monthly mortality rates $\left(z_{\mathrm{m}}\right)$ were calculated as:

$$
z_{\mathrm{m}}=1-\left(n_{(t+1)} / n_{(t)}\right)
$$

where $n_{(t)}$ is the number of fish in the cohort at time $t$ and $n_{(t+1)}$ is the number of fish remaining at the next time step, $t+1$ (1 mo later). Using only individuals $>40$ $\mathrm{mm}$ SL to calculate habitat-specific mortality minimized biases that could have resulted from: (1) migration of individuals following settlement or (2) differences in size selectivity between the gears used during the 1987 to 1988 and 2002 to 2003 surveys.

To determine nursery- and year-specific juvenile stage durations $(d)$, we tracked the mean length of fish during every month in each nursery habitat in order to estimate the time needed for cohorts entering our surveys at $40 \mathrm{~mm}$ to reach a mean size $>140 \mathrm{~mm}$. We selected this upper size limit because $>90 \%$ of the fish we collected were under this length, and, during months with very low catch rates, we did not want our estimates of stage duration to be biased by the pres- 


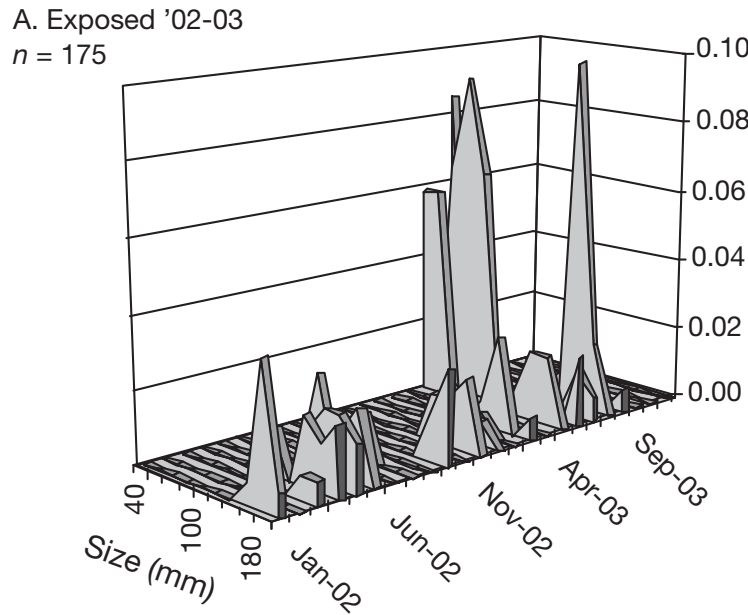

B. Bay '02-03

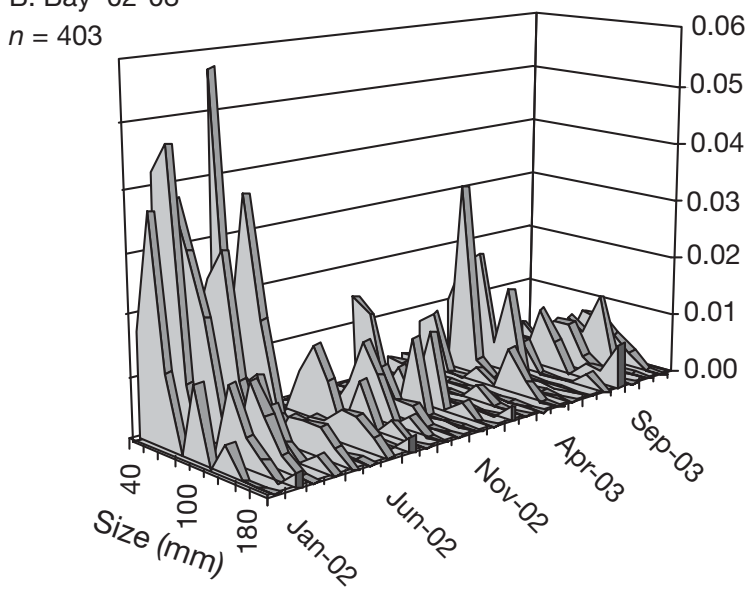

\section{Estuary '02-03}

$\mathrm{n}=395$

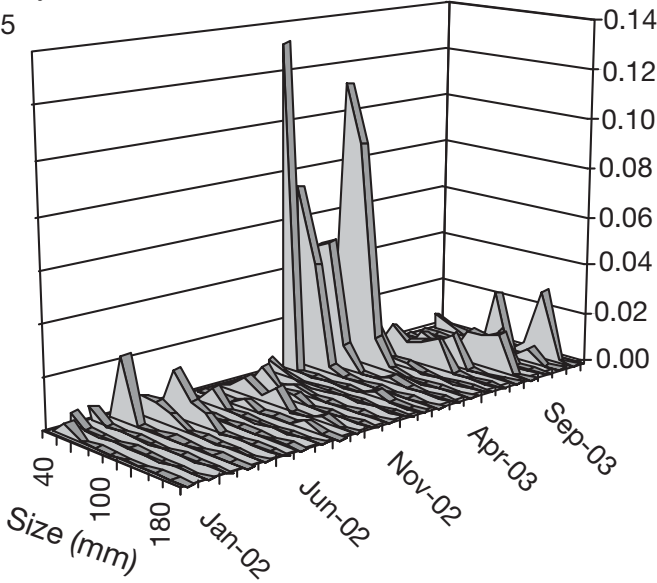

Fig. 2. Paralichthys californicus. Relative frequency of juvenile California halibut (in $20 \mathrm{~mm}$ standard length divisions) caught every month by otter trawling or seining in an: (A) exposed coast, (B) bay, or (C) estuary habitat from 2002 to 2003. These data, in addition to data from Kramer (1990) covering the years from 1987 to 1988, were used to calculate habitatspecific mortality and growth among habitats and years ence or absence of 1 or 2 large individuals. Also, this is the smallest size at which emigration out of the nursery habitat begins (Allen \& Herbinson 1990, Kramer 1991) and is therefore a useful length for estimating $d$. To account for the 10 to $40 \mathrm{~mm}$ individuals that we were not able to include in our analyses, we uniformly added 1 mo to each of our estimates of juvenile stage duration. This was done both in our surveys and with the data extracted from Kramer (1990).

The stage duration of halibut larvae was estimated to be $41 \mathrm{~d}$ (1.3 mo) (Gadomski \& Caddell 1991). The duration of the subadult stage was calculated as the time between $50 \%$ male and $50 \%$ female maturity (39 mo). The maximum age of halibut was invariant, regardless of juvenile habitat selection, and set at $20 \mathrm{yr}$ (240 mo). Reproductive effort $(f)$ of adults was estimated by Lavenberg (1987), who reported that females experience a reproductive season marked by $\sim 20$ events and that average batch fecundity of female halibut was 340000 (566 422 hydrated eggs $\mathrm{mo}^{-1}$ over $12 \mathrm{mo}$ in our models).

Subadult and adult halibut were surveyed by the California Department of Fish and Game off the coast of San Diego County in 1994 during the Southern California Bight Biomass Survey (SCBBS). The numbers of female subadult and adult halibut $>2$ yr old (based on size-at-age divisions of Love \& Brooks 1990) collected during the SCBBS were analyzed in a static life table to calculate annual (then monthly) mortality rates of subadult ( 2 to $4 \mathrm{yr}$ ) and adult ( $\geq 4 \mathrm{yr}$ ) fish.

It is difficult to link the vital rates of subadult and adult fish with any habitats they utilized in previous life stages, even if performance traits are carried over from one stage to the next. By quantifying differences in juvenile and subadult relative abundances within or from each nursery habitat in our study region, respectively, Fodrie \& Levin (2008) demonstrated that fish occupying estuarine nurseries were more likely to survive and be collected as subadults than fish occupying other nursery habitats. Based on those results (Fodrie \& Levin 2008), we corrected mortality data generated during the SCBBS so that subadults linked to estuary nurseries were characterized by a monthly mortality rate of 0.19 during the period from 2002 to 2003, while subadults that utilized exposed coast and bay nurseries were characterized by a monthly mortality rate of 0.20 (Table 2).

Demographic modeling and life-history examination. Following the collection of halibut vital-rate data, population growth rates were calculated from 12 stagebased matrix models generated for the 4 separate subpopulations that used alternative juvenile habitats (Fig. 1) during each of the $4 \mathrm{yr}$ we gathered data (exposed coast, bay, and lagoon habitats in 1987 to 1988; exposed coast, bay, and estuary in 2002 to 2003). 
Since inter-generational mixing among subpopulations was unknown, each nursery-associated matrix model examined halibut population demography as if only 1 habitat type was available to juveniles. Models were analyzed using 1 mo time steps, in order to match the approximate duration of the shortest stage (L) and the frequency of juvenile surveys. Using entries for each juvenile habitat and year, the 12 matrices were constructed to describe the change in a stage-structured population over time (from $t$ until $t+1$ ):

$$
\left|\begin{array}{l}
L_{t+1} \\
J_{t+1} \\
S A_{t+1} \\
A_{t+1}
\end{array}\right|=\left|\begin{array}{cccc}
P_{\mathrm{L}} & 0 & 0 & F_{\mathrm{A}} \\
G_{\mathrm{L}} & P_{\mathrm{J}} & 0 & 0 \\
0 & G_{\mathrm{J}} & P_{\mathrm{SA}} & 0 \\
0 & 0 & G_{\mathrm{SA}} & P_{\mathrm{A}}
\end{array}\right| \times\left|\begin{array}{l}
L_{t} \\
J_{t} \\
S A_{t} \\
A_{t}
\end{array}\right|
$$

where $G_{i}$ (stage growth) is the probability of surviving and advancing from stage $i$ to stage $i+1, P_{i}$ (stage survivorship) is the probability of surviving and remaining in the same stage, and $F_{\mathrm{A}}$ (fertility) is the reproductive contribution adults make towards Stage L. Methods for

Table 1. Paralichthys californicus. Length-frequency (40 to $220 \mathrm{~mm}$ standard length) and cohort table of California halibut captured each month within a bay habitat (Mission Bay) during 2002. Cohort tables provide the total number of juvenile halibut captured each month, the standardized number of fish surviving during each month $\left(l_{\mathrm{m}}\right)$, the standard number fish dying between months $\left(d_{\mathrm{m}}\right)$, and the mortality rate each month $\left(z_{\mathrm{m}}\right)$. Calculations of $l_{\mathrm{m}}, d_{\mathrm{m}}$, and $z_{\mathrm{m}}$ were begun following the peak in annual juvenile halibut abundance (February here). Negative mortality estimates were converted to zeros for estimating annual averages and, in some cases, excluded if related to low ( $<10$ individuals) capture rates (July, September, and December here)

\begin{tabular}{|c|c|c|c|c|c|c|c|c|c|c|c|c|c|}
\hline \multirow{2}{*}{$\begin{array}{l}\text { Sampling } \\
\text { period }\end{array}$} & \multirow[b]{2}{*}{$40-59$} & \multirow[b]{2}{*}{$60-79$} & \multirow[b]{2}{*}{$80-99$} & \multirow[b]{2}{*}{$100-119$} & \multicolumn{6}{|c|}{ Standard length (mm) } & \multicolumn{3}{|c|}{ Cohort table } \\
\hline & & & & & $120-139$ & $140-159$ & $160-179$ & $180-199$ & $200-219$ & $40-219$ & $l_{\mathrm{m}}$ & $d_{\mathrm{m}}$ & $z_{\mathrm{m}}$ \\
\hline Jan 2002 & 7 & 15 & 5 & 0 & 5 & 0 & 2 & 0 & 0 & 34 & & & \\
\hline Mar 2002 & 15 & 12 & 8 & 2 & 0 & 5 & 3 & 1 & 0 & 46 & 958 & 167 & 0.17 \\
\hline Apr 2002 & 6 & 10 & 12 & 4 & 1 & 3 & 1 & 0 & 1 & 38 & 792 & -63 & 0.00 \\
\hline May 2002 & 23 & 4 & 3 & 4 & 0 & 2 & 2 & 2 & 1 & 41 & 854 & 208 & 0.24 \\
\hline Aug 2002 & 0 & 0 & 3 & 5 & 3 & 0 & 0 & 0 & 1 & 11 & 229 & 146 & 0.64 \\
\hline Sep 2002 & 0 & 0 & 0 & 0 & 0 & 3 & 0 & 1 & 0 & 4 & 83 & -146 & 0.00 \\
\hline Oct 2002 & 0 & 0 & 0 & 2 & 5 & 3 & 0 & 1 & 0 & 11 & 229 & 125 & 0.55 \\
\hline Nov 2002 & 0 & 0 & 0 & 0 & 3 & 1 & 1 & 0 & 0 & 5 & 104 & 104 & 1.00 \\
\hline Dec 2002 & 0 & 0 & 0 & 0 & 0 & 0 & 0 & 0 & 0 & 0 & 0 & 0 & 0.00 \\
\hline $12 \mathrm{mo}$ avg. & & & & & & & & & & & & & 0.37 \\
\hline
\end{tabular}

Table 2. Paralichthys californicus. Stage-specific vital rates for California halibut utilizing exposed coast (La Jolla), bay (Mission Bay), lagoon (Agua Hedionda), or estuary (Tijuana River) juvenile habitats in 1987, 1988, 2002, and 2003. Rates are indexed to a 1 mo time step in demographic models. $f$ : fecundity; $z$ : mortality; $d$ : stage duration

\begin{tabular}{|c|c|c|c|c|c|c|c|c|c|c|c|c|}
\hline & \multicolumn{3}{|c|}{$\begin{array}{c}\text { Larvae } \\
(0-10 \mathrm{~mm})\end{array}$} & \multicolumn{3}{|c|}{$\begin{array}{c}\text { Juvenile } \\
(10-220 \mathrm{~mm})\end{array}$} & \multicolumn{3}{|c|}{$\begin{array}{c}\text { Sub-adult } \\
(220-475 \mathrm{~mm})\end{array}$} & \multicolumn{3}{|c|}{$\begin{array}{c}\text { Adult } \\
(>475 \mathrm{~mm})\end{array}$} \\
\hline & $f$ & $z$ & $d$ & $f$ & $z$ & $d$ & $f$ & z & $d$ & $f$ & $z$ & $d$ \\
\hline \multicolumn{13}{|c|}{ Exposed coast } \\
\hline 1987 & 0 & 0.99 & 1.3 & 0 & 0.97 & 9.0 & 0 & 0.20 & 39.0 & 566422 & 0.07 & 190.7 \\
\hline 1988 & 0 & 0.99 & 1.3 & 0 & 0.56 & 10.0 & 0 & 0.20 & 39.0 & 566422 & 0.07 & 189.7 \\
\hline 2002 & 0 & 0.99 & 1.3 & 0 & 0.68 & 10.0 & 0 & 0.20 & 39.0 & 566422 & 0.07 & 189.7 \\
\hline 2003 & 0 & 0.99 & 1.3 & 0 & 0.70 & 10.0 & 0 & 0.20 & 39.0 & 566422 & 0.07 & 189.7 \\
\hline \multicolumn{13}{|l|}{ Bay } \\
\hline 1987 & 0 & 0.99 & 1.3 & 0 & 0.41 & 11.0 & 0 & 0.20 & 39.0 & 566422 & 0.07 & 188.7 \\
\hline 1988 & 0 & 0.99 & 1.3 & 0 & 0.30 & 10.0 & 0 & 0.20 & 39.0 & 566422 & 0.07 & 189.7 \\
\hline 2002 & 0 & 0.99 & 1.3 & 0 & 0.37 & 10.0 & 0 & 0.20 & 39.0 & 566422 & 0.07 & 189.7 \\
\hline 2003 & 0 & 0.99 & 1.3 & 0 & 0.42 & 10.0 & 0 & 0.20 & 39.0 & 566422 & 0.07 & 189.7 \\
\hline \multicolumn{13}{|c|}{ Lagoon } \\
\hline 1987 & 0 & 0.99 & 1.3 & 0 & 0.45 & 10.0 & 0 & 0.20 & 39.0 & 566422 & 0.07 & 189.7 \\
\hline 1988 & 0 & 0.99 & 1.3 & 0 & 0.66 & 10.0 & 0 & 0.20 & 39.0 & 566422 & 0.07 & 189.7 \\
\hline \multicolumn{13}{|c|}{ Estuary } \\
\hline 2002 & 0 & 0.99 & 1.3 & 0 & 0.38 & 10.0 & 0 & 0.19 & 39.0 & 566422 & 0.07 & 189.7 \\
\hline 2003 & 0 & 0.99 & 1.3 & 0 & 0.31 & 11.0 & 0 & 0.19 & 39.0 & 566422 & 0.07 & 188.7 \\
\hline
\end{tabular}


calculating $G_{i}, P_{i}$, and $F_{\mathrm{A}}$ from $z, d$, and $f$ followed Crouse et al. (1987) and Caswell (2001). Both $P_{i}$ and $G_{i}$ are dependent on survival $\left(p_{i}\right)$ and growth $\left(\gamma_{i}\right)$ probabilities (Caswell 2001):

$$
\begin{aligned}
& P_{i}=p_{i}\left(1-\gamma_{i}\right) \\
& \text { and } G_{i}=p_{i} \gamma_{i} \\
& \text { where } p_{i}=\mathrm{e}^{\left(-z_{m}\right)} \\
& \text { and } \gamma_{i}=\left[\left(1-p_{i}\right) p_{i}{ }^{\left(d_{i}-1\right)}\right] /\left(1-p_{i}{ }^{\left(d_{i}\right)}\right)
\end{aligned}
$$

where $z_{m}$ is the monthly mortality rate and $d_{i}$ is the duration of the $i$ th stage (Crouse et al. 1987). We calculated average individual fertility $\left(F_{\mathrm{A}}\right)$ in the adult stage as:

$$
F_{\mathrm{A}}=(0.18)\left[\left(1+P_{\mathrm{A}}\right) f\right]
$$

where $f$ is average monthly fecundity of adults and $P_{\mathrm{A}}$ is calculated from Eq. (3). Eq. (7) is adapted from Caswell (2001) assuming $G_{\mathrm{A}}=0$ since halibut cannot grow out of the adult stage. The dominant eigenvalue $(\lambda)$ was determined in MATLAB (V 7.0.4; The Mathworks) for all 12 matrices we populated with habitatand year-specific entries.

These models were constrained by the following assumptions: (1) fish $>40 \mathrm{~mm}$ SL could be used to accurately estimate habitat-specific J-stage mortality, and fish between 10 and $140 \mathrm{~mm}$ could be used to estimate relative habitat-specific juvenile stage durations; (2) larval and adult vital rates were largely uninfluenced by juvenile habitat selection, and nurseryspecific vital rates were density-independent; and (3) $99.9 \%$ of eggs did not result in settled larvae, which produced models that were tuned for $\lambda \sim 1$ (a stable population not bounding toward zero or infinity).

For each matrix, changes in $\lambda$ resulting from changes in any 1 matrix entry can be evaluated using the sensitivity index $\left(S_{i j}\right)$, defined as:

$$
S_{i j}=\left(v_{i} W_{j}\right) /\langle\mathbf{w}, \mathbf{v}\rangle
$$

where $\mathbf{w}$ and $\mathbf{v}$ are the right and left eigenvectors associated with the dominant eigenvalue, $w_{j}$ is the $j$ th element of the first right eigenvector, $v_{i}$ is the $i$ th element of the first left eigenvector, and $\langle\mathbf{w}, \mathbf{v}\rangle$ is the scalar product of those vectors (Caswell 2000). Because matrix entries can differ greatly in magnitude, it is also useful to consider what impact a $1 \%$ change in $P_{i}, G_{i}$ and $F_{\mathrm{A}}$ would have on $\lambda$. Elasticities $\left(E_{i j}\right)$ sum to 1 and indicate the rank importance of matrix entries in determining population growth (de Kroon et al. 2000). This proportional sensitivity of individual matrix entries $\left(a_{i j}\right)$ can be calculated as:

$$
E_{i j}=\left(a_{i j} / \lambda\right) \times S_{i j}
$$

Elasticities demonstrate how much impact a change in a matrix entry should have on $\lambda$ and are considered a prospective analysis. Another measure is needed to quantify how spatial and temporal differences in vital rates generate variation in $\lambda$ (Caswell 2000). Therefore, retrospective contribution analyses were employed to determine the role of individual matrix entries in producing observed growth rates. These life table response experiments (LTREs) were used to examine the sources of variation in $\lambda$ among habitats and years. Contribution $\left(C_{i j}\right)$ values for each matrix entry were calculated as:

$$
C_{i j}=\left(a_{i j}{ }^{(k)}-a_{i j}^{(\cdot)}\right) \times S_{i j} \mid\left(M^{(\mathrm{k})}+M^{(\cdot)}\right) / 2
$$

where $a_{i j}{ }^{(k)}$ is the value of matrix entry $a_{i j}$ in the $k$ th matrix, and $a_{i j}{ }^{(\cdot)}$ is the average value of matrix entry $a_{i j}$ from all matrices. $S_{i j}$ is the sensitivity of $\lambda$ to matrix entry $a_{i j}$, evaluated using the average of the $k$ th and overall average matrices $(M)$ (Caswell 2000). To generate LTREs that could be used for comparisons among habitats during 1987, 1988, 2002, and 2003, $M^{(\cdot)}$ values used in Eq. (10) were constructed from the means of vital rates across all juvenile habitat alternatives during each year.

To further explore the consequences of juvenile habitat utilization on overall population demography, we integrated habitat-specific vital rates and the relative degrees to which alternative juvenile habitats were utilized. We calculated overall population growth rates from a series of simulations in which the vital rates used to populate matrix entries were derived from the habitat-specific vital rates $f, z$, and $d$, weighted by the percentage of fish that utilized exposed coast versus embayment habitats (bay, lagoon, and estuary rates were pooled into a single embayment value). This was done separately for each year in which we had juvenile data, and projected $\lambda$ for the local California halibut population across a gradient of habitat utilization from all juvenile fishing using exposed coast habitat to all fish using embayment habitat.

\section{RESULTS}

Population growth rates $\left(\lambda \mathrm{mo}^{-1}\right.$; mean \pm 1 standard deviation) averaged over the $4 \mathrm{yr}$ for which we obtained juvenile vital-rate data were $0.97 \pm 0.03,1.14$ $\pm 0.04,1.03 \pm 0.06$ and $1.17 \pm 0.02$, for subpopulations of California halibut that utilized exposed coast, bay, lagoon, or estuary habitat as juveniles, respectively. Subpopulations in which juveniles utilized bay and estuary habitat were characterized by $\lambda>1$ in every year. Conversely, the subpopulation that utilized exposed coast habitat as juveniles were characterized by $\lambda<1$ in all years except $1988(\lambda=1.01)$, while the halibut that utilized lagoon habitat as juveniles were defined by $\lambda$ values of 1.08 (1987) and 0.98 (1988). 
Overall, $\lambda$ ranged from a low of 0.93 (exposed coast, 1987) to a high of 1.20 (bay, 1988).

The prospective approach (elasticity) for identifying critical life-history vital rates showed that population growth was most sensitive to changes in adult stage survival $\left(P_{\mathrm{A}}\right)$ and, to a lesser extent, subadult $\left(P_{\mathrm{SA}}\right)$ and juvenile stage survival $\left(P_{\mathrm{J}}\right)$ (Fig. $3 \mathrm{~A}$ to $\left.\mathrm{D}\right)$. This trend was most pronounced at the exposed coast site, but held true for all habitats and years. Changes in stage growth rates $\left(G_{\mathrm{L}}, G_{\mathrm{J}}\right.$, and $\left.G_{\mathrm{SA}}\right)$ and fertility $\left(F_{\mathrm{A}}\right)$ had more modest impacts on $\lambda$, and $\lambda$ appeared insensitive to changes in larval stage survival $\left(P_{\mathrm{L}}\right)$ (Fig. 3A to D).

However, LTREs revealed that variation in the lifehistory vital rates to which $\lambda$ was theoretically most sensitive $\left(E_{i j}\right)$ were not required to generate notable differences in $\lambda$ among subpopulations utilizing alternative juvenile habitats and across years. For instance, elasticity was greatest for adult stage survival $\left(P_{\mathrm{A}}\right)$, but this rate varied little among the 4 subpopulations we considered and did not contribute $\left(C_{i j}\right)$ significantly to differences we observed in population growth. Rather, stage growth of juvenile fish becoming subadult fish $\left(G_{J}\right)$ had a significant contribution to variation in population growth (Fig. 3E to $\mathrm{H}$ ). Thus, although $P_{\mathrm{A}}$ appears to be the dominant driver of $\lambda$, juvenile vital rates also appear capable of generating large differences in population growth based on contribution analyses (ranging from a 3\% decline to a $20 \%$ increase in our analyses). Among habitats, juvenile stage growth $\left(G_{\mathrm{J}}\right)$ contributed during all years to below-average popula-
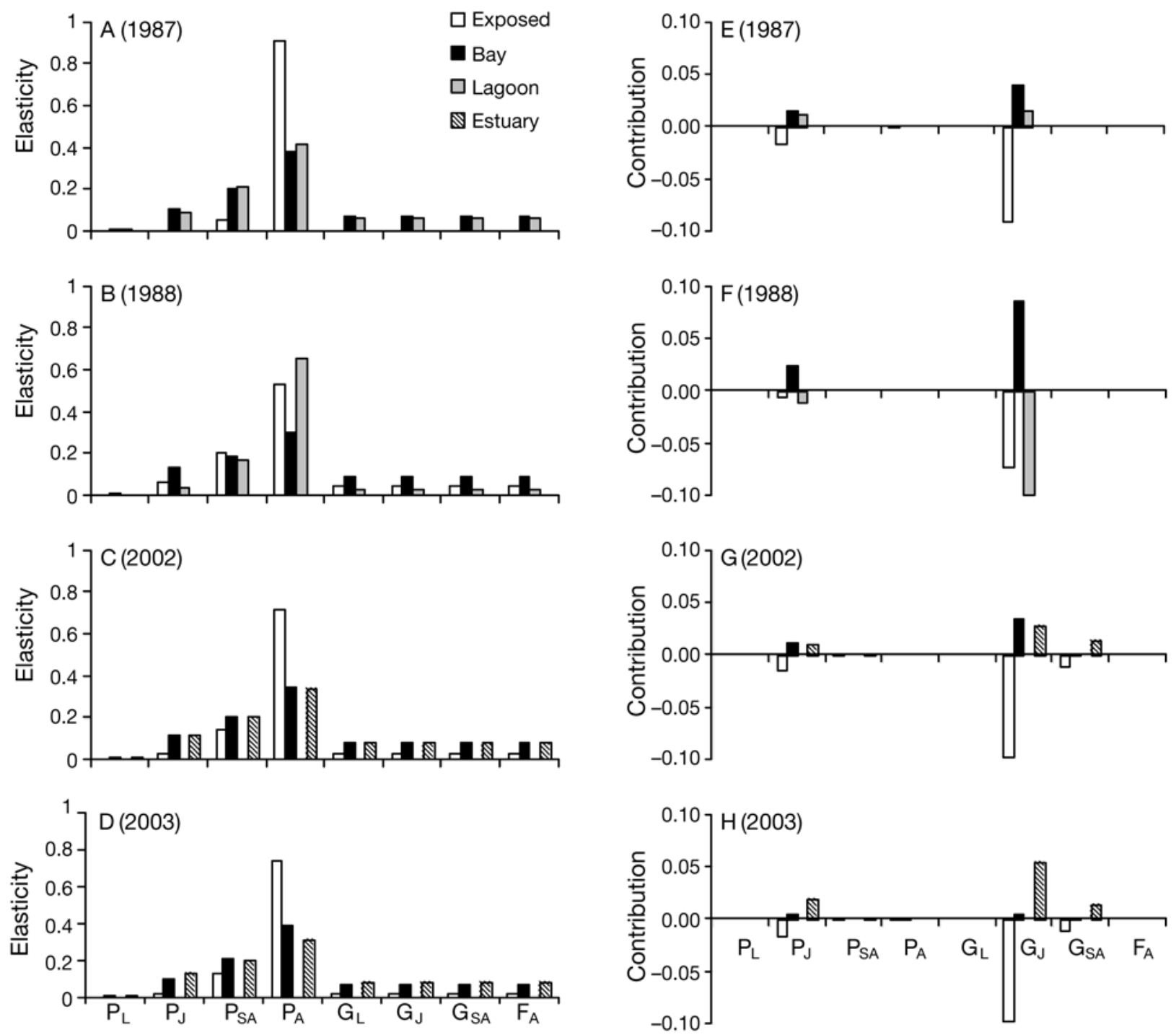

Fig. 3. Paralichthys californicus. (A to D) Elasticity and (E to H) contribution of each matrix element to changes in $\lambda$ during: (A, E) 1987, (B, F) 1988, (C, G) 2002, and (D, H) 2003, for the subpopulations utilizing exposed coast (La Jolla), bay (Mission Bay), lagoon (Agua Hedionda), and estuary (Tijuana River) nurseries 
tion fitness at the exposed coast site and above-average population fitness in the bay and estuary sites. Habitat effects on population growth were not always constant; for instance, $G_{J}$ for the lagoon subpopulation during 1987 contributed toward an elevated $\lambda$ relative to average juvenile habitat conditions, but not during the following year (Fig. 3E, F).

Population growth weighted by habitat utilization (exposed coast versus embayment) was positively, curvilinearly correlated with the percentage of juvenile fish that utilized embayment habitats as nurseries each year. Population growth appeared highest in 1988 and most negative in 1987, but to determine an exact $\lambda$ would require knowing the actual percentage of embayment utilization by juvenile fish in each year (Fig. 4). These simulations indicated that in order to maintain a stable or growing overall halibut population during each year $(\lambda \geq 1)$, at least $70,0,38$, and $40 \%$ of juveniles must have utilized coastal embayments as nurseries during 1987, 1988, 2002, and 2003, respectively.

\section{DISCUSSION}

Whether a juvenile habitat promotes negative, stable, or positive population growth can be independent from the number of recruits it contributes towards replenishing older populations. Rather than nursery contribution, it is the growth and survivorship rates during juvenile habitat utilization, in concert with the relative number of juveniles that utilize each habitat alternative, which determines how the juvenile stage affects overall population growth. This has strong, but

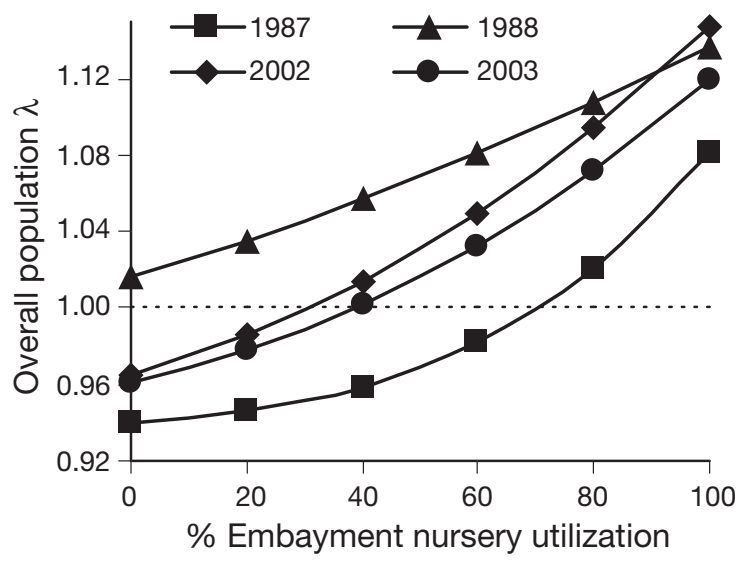

Fig. 4. Paralichthys californicus. Overall population growth resulting from simulations of California halibut demography in relation to the percentage of fish that utilized exposed coast versus embayment (bay, lagoon, or estuary) habitat as nurseries during 1987, 1988, 2002, and 2003. Dashed line represents a stable population $(\lambda=1)$ potentially under-appreciated, relevance for species persistence and fishery conservation strategies based on juvenile habitat protection. Fodrie \& Levin (2008) used elemental fingerprinting of otoliths to estimate that $\sim 42 \%$ of California halibut Paralichthys californicus recruits that advanced from the juvenile to subadult stage in this region had utilized exposed coast habitats from 2003 to 2004. This contribution of recruits from the exposed coast implied that this habitat is a highly productive nursery for this species. However, our demographic data demonstrate that the production of recruits from exposed coasts should have also contributed toward depressed juvenile stage growth $\left(G_{\mathrm{J}}\right)$ for the overall halibut population in our study region. Of the 4 habitat alternatives, the exposed coast subpopulation had the tightest juvenile bottleneck in which many settling larvae entered the system, but only a comparatively small percentage of successful recruits advanced to the subadult stage (even if the raw number of recruits was large). As a result, the juvenile cohort utilizing exposed coast habitats contributed to negative population growth in 3 of the $4 \mathrm{yr}$ we considered and functioned as a demographic sink. During the 4 yr we obtained vital-rate data from nearshore habitats of San Diego County, our simulation models suggested that, in order to maintain a stable or growing halibut population along this section of coast $(\lambda>1), \geq 40 \%$ of all juveniles needed to have utilized embayment nurseries (Fig. 4). Over the long term, it appears the exposed coast subpopulation must be subsidized by migrants from embayment habitats through adult mixing or larval transport in order to persist (Morris 1991).

Two widely used frameworks for measuring nursery value for marine fauna include: (1) total contribution of new recruits to the adult stock (effective juvenile habitat; Gibson 1994, Dahlgren et al. 2006) and (2) unitarea production of biomass that is contributed to the adult stock (the nursery-role concept; Beck et al. 2001). Both frameworks have been created to help direct resources towards conservation efforts that will have the greatest benefit in maintaining healthy fish and invertebrates stocks. However, under either of these schemes it is possible to have a high total or unit-area contribution from a juvenile habitat that would simultaneously reduce overall population fitness. Simply having local settlement that far exceeds a habitat's carrying capacity could result in high juvenile mortality, as reported for other finfish species (i.e. the 'concentration hypothesis'; Iles \& Beverton 2000), and yet allow for relatively high unit-area or raw nursery contribution. For instance, previous elemental fingerprinting results involving the California halibut suggest that ranked unit-area contribution (nursery-role concept) of juvenile fish from nearshore habitats within our study 
region is: estuary $>$ lagoon $>$ bay $>$ exposed coast habitat; while total recruit contribution (effective juvenile habitat) is ranked as: bay > exposed coast > lagoon > estuary habitat (Fodrie \& Levin 2008). If fitness $(\lambda)$ is considered as the metric for nursery value, the ranking becomes: estuary > bay > lagoon > exposed coast habitat. These are 3 distinct and somewhat conflicting approaches to ranking nursery function among these 4 habitat types for juvenile California halibut. Thus, the different criteria for habitat value will have a strong influence on the sites that managers target for protection, and specific conservation goals (e.g. harvest, sustainability, spillover) may dictate which framework is most desirable (sensu Crowder et al. 2000). These different rankings may also highlight the potential advantages of conservation plans that maintain habitat diversity, which could support the bet-hedging strategy employed by this (and presumably other) species. Some habitats help sustain biomass in the adult stock regardless of juvenile mortality costs (e.g. exposed coast), while others promote $\lambda>1$ even if they contribute little in terms of raw biomass (e.g. estuary).

Including conferred population fitness as a metric of nursery value, a technique that considers the influence of each life-history stage, seems particularly advantageous for species in which the relative impacts of perturbations to both early (e.g. habitat degradation, bycatch) and late (e.g. harvest) life-history stages of a fluctuating population confound one another (Crouse et al. 1987). Therefore, it is surprising that the quantitative impact of juvenile habitat utilization on finfish demography has been neglected as a management tool. Previously, Levin \& Stunz (2005) did utilize stage-structured models of red drum Sciaenops ocellatus to demonstrate that comprehensive wetlands restoration could lead to a $2 \%$ increase in population growth without any changes in fishing practices. This change resulted in a shift from negative to positive population growth for this species, and, along with our data, highlights the advantages of considering population demography to identify essential fish habitats. Further examining life histories through sensitivity analyses $\left(E_{i j}\right)$ of population growth to stage-specific vital rates offers yet another valuable conservation tool (Mangel et al. 2006). However, vital-rate contributions $\left(C_{i j}\right)$ for California halibut suggested that juvenile stage growth $\left(G_{J}\right)$ could have an important role in regulating $\lambda$, even though this was not expected based on our elasticity analyses (Fig. 3). Therefore, an approach that considers both prospective (sensitivity) and retrospective (life table response experiments) analyses may be best.

Average population growth for the $4 \mathrm{yr}$ we obtained juvenile cohort data was $1.03 \mathrm{mo}^{-1}$. This is equivalent to $42 \%$ population growth $\mathrm{yr}^{-1}$, and must be an overestimation of population fitness, although halibut pop- ulations may be growing in response to restrictions placed on trawl and trammel nets during the 1990s (Fodrie pers. obs.). As with any model, we can consider how each of our assumptions influenced this result. (1) Fish > $40 \mathrm{~mm}$ SL could be used to accurately estimate habitat-specific J-stage mortality, and fish between 10 and $140 \mathrm{~mm}$ could be used to estimate relative habitat-specific J-stage growth. We were unable to assess mortality for juvenile halibut $<40 \mathrm{~mm}$ SL due to gear biases and post-settlement migration. Since predation risk generally decreases with size, this likely biased survivorship upward and subsequently inflated $\lambda$. Furthermore, mortality risk for very small juveniles may not be equal among nursery alternatives. Because estuarine environments are almost always found to enhance survivorship or growth of juvenile fish over exposed coast habitats (sensu Heck et al. 2003); however, we do not expect these potential differences would alter our conclusions about the relative nursery value of alternative habitats in supporting halibut population growth. Also, using only 10 to $140 \mathrm{~mm}$ fish to estimate the duration of the juvenile stage should have increased $G_{\mathrm{J}}$ and produced elevated measures of $\lambda$. Again, this should not have affected our betweenhabitat comparisons, however, as our measures of $d$ agree with previous research that has documented relatively small differences in halibut growth rates among nursery alternatives (Kramer 1991). (2) Larval and adult vital rates were largely uninfluenced by juvenile habitat selection, and habitat-specific vital rates were density independent. Although larval- and adult-stage vital rates may not vary as a function of juvenile habitat selection/utilization (larval rates appear to be particularly buffered against this, as almost all larvae settle along the open coast and then migrate into bay, lagoon, or estuary habitats post-settlement; Fodrie unpubl. data), there is little doubt they vary in time. For instance, population projection matrix models have previously demonstrated that El Niño cycles have strong impacts on a tide pool fish, Clinocottus analis, in southern California due to changes in fertility (Davis \& Levin 2002). Likewise, we observed strong differences in $\lambda$ values during the El Niño and La Niña years of 1987 and 1988. Recruitment pulses from all juvenile habitats, and therefore population growth, appeared to be much higher during the cool, La Niña year of 1988 (Fig. 4). Halibut reproduction could also be impacted by El Niño/La Niña cycles, and limited estimates of larval mortality, as well as size-specific fecundity, should be viewed as potential sources of error in our models. We do expect our results are valid across low- and high-settlement years, since previous work has indicated that juvenile vital rates appear independent of local density in this region (Fodrie \& Levin 2008). (3) $99.9 \%$ of eggs did not result in settled larvae, which 
produced models that were tuned for $\lambda \sim 1$. Fitness should be least sensitive to the life-history vital rates that experience greatest variability (Pfister 1998). In our models, population growth was most insensitive to changes in larval survival $\left(P_{\mathrm{L}}\right)$, buffering our results against uncertainty in larval vital rates (Fig. 3). However, this also suggests high variability (temporally and spatially) of larval mortality relative to other vital rates; this is predictable given California halibut reproductive life history.

There are additional reasons to view our results as approximate rather than exact measures of population dynamics for this species. First, we were only able to conduct limited surveying during 2002 and 2003 to generate mortality estimates at La Jolla, Mission Bay, and Agua Hedionda. Although our demographic results were largely conserved between models generated from 2002 to 2003 collections and data extracted from Kramer's more extensive 1987 to 1988 surveys, we recognize that our sampling design was not capable of fully exploring spatial differences in survivorship that may occur within each site (e.g. shallower versus deeper, mudflat versus structured/vegetated bottoms). Furthermore, our sampling occurred within single, representative sites to quantify juvenile vital rates for exposed coast, bay, lagoon, and estuary habitats. Understanding the full range of spatial and temporal variability in halibut vital rates, even among locations defined as the same type of juvenile habitat (e.g. Mission and San Diego bays within our study region), would require further effort. Beyond the limits of San Diego County (e.g. northern California), our data should only be applied to halibut stocks after careful inspection to determine if vital-rate data are transferrable. Therefore, we have focused on the broader implications of nursery-driven differences in $\lambda$ rather than attempting to generate high-resolution forecasts of population growth for halibut along this section of the southern California coast. Second, the $C_{i j}$ results we observed represent both the natural variability resulting from nursery habitat heterogeneity, but also the known range of values for this species' stagespecific vital rates generated during the present study or available in the published literature. Vital-rate data gaps are frequently encountered in demographic modeling of wild populations (Heppell et al. 2000), and quantifying variation in vital rates among years, particularly for larval and adult stages, remains a priority for future work with this species. Most importantly, having these data could allow managers to better define the life-history stages that are critical for halibut population persistence and, subsequently, to target conservation efforts accordingly (e.g. adult harvest versus juvenile habitat quality). From this perspective, there is considerable benefit to be gained from basic life-his- tory studies that could be used to fully populate demographic matrices.

Even with these challenges to demographic modeling in mind, our results reveal large differences in $\lambda$ among juvenile subpopulations that are likely robust in the face of some modeling uncertainty. Thus, habitat-specific differences in juvenile survivorship and growth have the potential to generate significant nursery-driven changes in population growth. A key aid for preserving coastal ecosystems essential for nearshore fishery species is the ability to link location-specific differences in vital rates with overall population fitness $(\lambda)$. It follows that siting protocols that include demographic consequences of nursery utilization should allow targeted conservation of those habitats that act as productivity 'hotspots' (Crowder et al. 2000). Currently, this deserves more consideration in evaluating the nursery function of juvenile habitats, and although applied to a fish here, is a useful approach for many terrestrial and marine species.

Acknowledgements. This work was funded by California Environmental Quality Initiative and National Science Foundation fellowships to F.J.F., as well as a California Department of Boating and Waterways agreement (03-106-104) and a National Science Foundation grant (OCE 03-27209) to L.A.L. We appreciate the technicians who helped during juvenile surveys. Survey data from S. Kramer were invaluable, and S. Wertz of the California Department of Fish and Game provided halibut catch data for the 1994 SCBBS. Suggestions from R. Lande, J. Hunter, and several anonymous reviewers significantly improved this manuscript.

\section{LITERATURE CITED}

Allen MJ, Herbinson KT (1990) Settlement of juvenile California halibut, Paralichthys californicus, along the coasts of Los Angeles, Orange, and San Diego Counties in 1989. CCOFI Rep 33:84-96

Beck MW, Heck Jr KL, Able KW, Childers DL and others (2001) The identification, conservation and management of estuarine and marine nurseries for fish and invertebrates. Bioscience 51:633-641

Caswell H (2000) Prospective and retrospective perturbation analyses: their roles in conservation biology. Ecology 81:619-627

Caswell H (2001) Matrix population models: constraints, analysis and interpretation. Sinauer Associates, Sunderland, MA

> Crouse DT, Crowder LB, Caswell H (1987) A stage-based population model for loggerhead sea turtles and implications for conservation. Ecology 68:1412-1423

Crowder LB, Lyman SJ, Figueira WF, Priddy J (2000) Source-sink population dynamics and the problem of siting marine reserves. Bull Mar Sci 66:799-820

> Dahlgren CP, Kellison GT, Adams AJ, Gillanders BM and others (2006) Marine nurseries and effective juvenile habitats: concepts and applications. Mar Ecol Prog Ser 312: 291-295

> Davis JLD, Levin LA (2002) Importance of pre-recruitment life-history stages to population dynamics of the woolly 
sculpin Clinocottus analis. Mar Ecol Prog Ser 234:229-246 de Kroon H, van Groenendael J, Ehrlen J (2000) Elasticities: a review of methods and model limitations. Ecology 81:607-618

Doak P, Kareiva P, Kingsolver J (2006) Fitness consequences of choosy oviposition for a time-limited butterfly. Ecology 87:395-408

Ferren Jr WR, Fiedler PL, Leidy RA (1996) Wetlands of the central and southern California coast and coastal watersheds: a methodology for their classification and description. United States Environmental Protection Agency, San Francisco, CA

Fodrie FJ, Levin LA (2008) Linking juvenile habitat utilization to population dynamics of California halibut. Limnol Oceanogr 53:799-812

> Fodrie FJ, Mendoza G (2006) Availability, usage and expected contribution of potential nursery habitats for the California halibut. Estuar Coast Shelf Sci 68:149-164

Gadomski DM, Caddell SM (1991) Effects of temperature on early-life-history stages of California halibut, Paralichthys californicus. Fish Bull 89:567-576

Gerber LR, Heppell SS, Ballantyne F, Sala E (2005) The role of dispersal and demography in determining the efficacy of marine reserves. Can J Fish Aquat Sci 62:863-871

Gibson RN (1994) Impact of habitat quality and quantity on the recruitment of juvenile flatfishes. Neth J Sea Res 32: 191-206

Gillanders BM, Able KW, Brown JA, Eggleston DB, Sheridan PF (2003) Evidence of connectivity between juvenile and adult habitats for mobile marine fauna: an important component of nurseries. Mar Ecol Prog Ser 247:281-295

Grinnell J (1917) The niche-relationships of the California thrasher. Auk 34:427-433

- Heck Jr KL, Hays G, Orth RJ (2003) Critical evaluation of the nursery role hypothesis for seagrass meadows. Mar Ecol Prog Ser 253:123-136

Heppell SS, Caswell H, Crowder LB (2000) Life histories and elasticity patterns: perturbation analysis for species with minimal demographic data. Ecology 81:654-665

Iles TC, Beverton RJH (2000) The concentration hypothesis: the statistical evidence. ICES J Mar Sci 57:216-227

Editorial responsibility: Jana Davis, Annapolis, Maryland, USA
Kauffman MJ, Frick WF, Linthicum J (2003) Estimation of habitat-specific demography and population growth for peregrine falcons in California. Ecol Appl 13:1802-1816

Kramer SH (1990) Distribution and abundance of juvenile California halibut, Paralichthys californicus, in shallow waters of San Diego County. Fish Bull Calif Dep Fish Game 174:99-126

Kramer SH (1991) Growth, mortality, and movements of juvenile California halibut, Paralichthys californicus, in shallow coastal and bay habitats of San Diego County, California. Fish Bull 89:195-207

Lavenberg RJ (1987) Reproductive biology of the California halibut. Report to the Southern California Sportfish Assessment Program. Long Beach, CA

> Lefkovitch LP (1965) The study of population growth in organisms grouped by stages. Biometrics 21:1-18

Levin PS, Stunz GW (2005) Habitat triage for exploited fishes: Can we identify essential 'Essential Fish Habitat'? Estuar Coast Shelf Sci 64:70-78

Limburg KE (2001) Through the gauntlet again: demographic restructuring of American shad by migration. Ecology 82:1584-1596

Love MS, Brooks A (1990) Size and age at first maturity of the California halibut, Paralichthys californicus, in the southern California Bight. Fish Bull Calif Dep Fish Game 174: $167-174$

> Mangel M, Levin P, Patil A (2006) Using life history and persistence criteria to prioritize habitats for management and conservation. Ecol Appl 16:797-806

- Morris DW (1991) On the evolutionary stability of dispersal to sink habitats. Am Nat 137:907-911

Moser HG, Pommeranz T (1999) Vertical distribution of eggs and larvae of northern anchovy, Engraulis mordax, and of the larvae of associated fishes at two sites in the Southern California Bight. Fish Bull 97:920-943

Petersen CGJ (1896) The yearly immigration of young plaice into the Limfjord from the German Sea. Report to the Danish Biological Station 6:1-48

- Pfister CA (1998) Patterns of variance in stage-structured populations: evolutionary predictions and ecological implications. Proc Natl Acad Sci USA 95:213-218

Submitted: August 11, 2008; Accepted: April 21, 2009

Proofs received from author(s): June 12, 2009 